\title{
ESTILOS DE VIDA FAMILIAR Y RIESGO SOCIAL INFANTIL
}

\author{
DR. D. AGUSTIN BUENO BUENO
}

Profesor del Departamento de Psicología de la Salud. Universidad de Alicante

\section{INTRODUCCION}

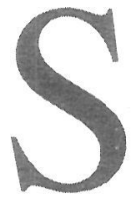

iempre que, en medicina o psicología, se emplea la noción de riesgo se hace en referencia a una situación de peligro probable. Este peligro se estudia en función de unos índices o características situacionales o comportamentales, que son las que marcan su probabilidad e incidencia en la población. El mayor significado de los estudios de riesgo radica en su funcionalidad preventiva. No obstante, hablar de riesgo social puede resultar extraño por lo novedoso. De hecho el alcance y significado del riesgo social es el mismo, pero desde la óptica de unas disciplinas de visión más amplia como pueden ser la psicosociología y el trabajo social.

En el término «riesgo social» nos encontramos con una expresión de carácter aparentemente generalizador, frente a lo concretos que suelen ser la mayoría de los riesgos identificados como enfermedad o discapacidad. El riesgo social mira hacia una población encaminada hacia una alteración de tipo más amplio, pero concretizable en el peligro de llegar a una situación de marginación social.

Esta marginación social general la entendemos relativa a factores socioeconómicos, por cuanto el factor económico tiene de valor exponencial en nuestra sociedad (APISMA-GESE, 1981) y en delimitación con las marginaciones sociales específicas (de minusvalías, raciales, sexuales, etc.).

No obstante el carácter general de la marginación social debida a factores socioeconómicos, ésta tiene, en la población infantil que es donde se puede hablar de riesgo en tal sentido, traducciones tan concretas como el retraso, fracaso o inadaptación escolar, o las conductas inadaptadas o delictivas, o incluso determinadas desigualdades en salud física.

Tiene sentido, evidentemente, hablar de riesgo social, con el significado que acabo de explicar, sólo en la población infantil. En el caso de la población adulta el riesgo social ya ha cristalizado en una inadaptación, más o menos abierta; estaremos ante un enfermo, ante una 
alteración, que requerirá tratamiento pero no prevención. Es durante la infancia y adolescencia cuando cabe hablar de riesgo de inadaptación. El peligro está a la vista, pero admite todavía medidas de intervención preventiva.

Por otra parte, es bien sabido que tanto en psicodiagnóstico como en el tratamiento de cualquier problemática (bio-psico-social) infantil, tanto la toma de datos, como la aportación de recursos está mediada por los adultos que tienen a su cuidado al niño.

En el caso de los estilos de vida esto es, aún si cabe, más evidente. La forma de vida en que se cría un niño, y no me refiero sólo a las ya clásicas «prácticas de crianza», sino a su ¿cómo vital?, a los modos con los cuales se produce su paulatina entrada en sociedad, adquieren forma y sentido en el medio familiar; y es a él a quien debemos remitirnos básicamente para apreciar aquel riesgo social, como luego para intentar evitar la inadaptación.

\section{PLANTEAMIENTO}

Es: bastante fácil y frecuente, por desgracia, observar que los niños en sitıación de mayor riesgo social son los que pertenecen a los estratos sociales inferiores.

Sin embargo, esta relación entre status socioeconómico bajo y peligro de futura marginación social del niño, tampoco es tan lineal que permita predecirlo y prevenirlo con cierta precisión cuando el niño es todavía bastante pequeño, y no ha entrado aún en la espiral marginante.

Cabe pensar que los estilos de vida familiar, en los cuales el niño va a desarrollarse y socializarse, son las variables intermedias, o mediadoras, entre el status - como variable ambiental global-y la conducta futura del niño. Mediación que, en buena medida, se hará a partir de los desequilibrios que ofrezca el medio sociofamiliar (directamente condicionado pơr el estatus, no estrictamente por los ingresos económicos) y de los instrumentos reequilibradores de que disponga el mismo medio (J. Piaget, 1975). Estas constancias del medio, en el doble juego de desequilibrios-equilibrios, suponen el elemento central del desarrollo, más cualitativo que cuantitativo, de las estructuras y estilos cognitivos del niño. Dicho en términos de la concepción evolutiva de Vygotski sería la ineludible incidencia del contexto sociofamiliar en la «zona de desarrollo próximo del niño» (L. S. Vygotski, 1989).

Los estilos de vida familiar también pueden considerarse mediadores del desarrollo infantil en la medida en que son, de hecho, «características funcionales del medio" (A. Bueno, 1990). Por el hecho de ser características funcionales del medio, los estilos de vida son variables dinámicas y, por tanto, difíciles de analizar con precisión. Solemos recurrir en nuestros estudios a las características estructurales del 
medio sociofamiliar (zona urbana, ingresos, estudios, profesión, número de miembros, metros de vivienda...). La mayoría de nuestros informes sociales están cubiertos con este tipo de variables, que son asequibles, objetivables, y utilizables para la administración de recursos económicos.

Estudiar cómo funcionan las personas en su medio sociofamiliar resulta bastante más complicado, pero en la medida en que se llega a conocer esta dimensión, muy relacionada sí con la estructural, se pueden proponer líneas de intervención también dinámicas y operativas del profesional.

En cuanto características funcionales del medio, los estilos de vida familiar representan formas o pautas con las cuales se desenvuelven los adultos, y por derivación los niños, en ese medio social. Los estilos de vida, por otra parte, son formas generalizadas de funcionar las personas en ese medio, porque significan modos adaptativos de responder a las características y exigencias del contexto social, sobre todo cuando se trata de un contexto social muy extremado.

El estudio de formas o estilos de vida parciales ha sido con frecuencia realizado como búsqueda de algún elemento determinante de la conducta social. Ordinariamente se ha estudiado la influencia de una faceta concreta de la vida familiar, así: J. Lautrey (1985) la organización del medio familiar en el desarrollo intelectual; P. Howes y H. J. Markman (1989) la comunicación intrafamiliar con la sociabilidad; C. H. Hart y Colaboradores (1990) el tipo de disciplina materna y la integración escolar...

La intención al iniciar este estudio era crear un instrumento de obtención de datos sobre una variedad de estilos de vida que fuese sencillo de emplear y que estuviese relacionado tanto con el status socioeconómico como con el riesgo social.

Excluíamos la observación por tratarse de facetas bastante delicadas de la vida familiar, que no resultan sencillas de observar con espontaneidad; y excluíamos el cuestionario porque necesariamente habría de ser muy extenso y problemático para una población de bajo nivel sociocultural. Optamos por una entrevista semiestructurada que se cerraba posteriormente en una escala de puntuaciones.

\section{DESCRIPCION DE LA ESCALA Y FORMA DE EMPLEO}

Con este planteamiento de base se ha construido una escala que comprende seis facetas de la vida familiar:

1. Hábitos: de alimentación, de higiene y de salud.

2. Organización del medio familiar: se trata de ver si la estructuración de la vida familiar es predominantemente flexible, o rígida o laxa, o una cierta combinación de las anteriores. 
3. Comunicación intrafamiliar: que comprende tanto la presencia, frecuencia y tipo de contactos diarios del niño con el padre y la madre, como la expresión afectiva en términos de malos tratos entre adultos y hacia el niño, sobreprotección, indiferencia, rechazo.

4. Métodos disciplinares: que incluye el tipo de refuerzos más frecuentes empleados con el niño y la adecuación, congruencia y proporción entre sanción y motivo de la misma.

5. Concepción de la vida: autogratificaciones, creencias mágicas, confianza en el azar.

6. Modelos de identificación y aprendizaje: presencia de adultos en convivencia familiar con el niño y con conductas socialmente inadaptadas o patológicas. En estricto sentido este apartado de «modelos...» no responde al concepto de estilo de vida que hemos esbozado al principio. Pero sí son un dato globalizador de un ambiente familiar enrarecido, que ha de afectar negativamente a la dinámica del grupo y al desarrollo del niño. Con este valor de elemento globalizador está incluido en la escala.

La escala obtiene una puntuación, según la intensidad apreciada, en cada una de las seis facetas indicadas. Obtenemos también una séptima como total de la escala de riesgo social.

Hay que tener en cuenta que como se valoran aspectos negativos de los estilos de vida familiar, las puntuaciones obtenidas son indicadoras de conflictividad en cada una de las facetas. Significa también, como siempre en este tipo de escalas, que una puntuación baja o nula no indica una calidad óptima de vida, sino simplemente que en la recogida de datos no se han apreciado facetas negativas; en cambio cuando la puntuación es elevada sí podemos afirmar que existe tal conflictividad.

A estas puntuaciones se llega a partir de una entrevista semiestructurada. En ella, inicialmente, se pide a la madre y/o padre que explique «¿cómo es un día normal (laboral) de su hijo?», y a continuación «¿cómo es un día festivo del niño?». En estas dos amplias preguntas hay que dejar hablar, tomar notas, y sólo interrumpir para pedir aclaraciones de algo no entendido, o para animar a que continúe la explicación.

Posteriormente se pasa a matizar con preguntas concretas los seis apartados de la escala, sobre todo en aquellos en que no haya aparecido suficiente información.

\section{VARIABLES E HIPOTESIS DEL ESTUDIO}

La escala, de la forma indicada, se ha aplicado a 59 niños de 6 a 14 años. De ellos 25 eran niños atendidos en un Centro de Salud por 
afecciones de escasa importancia, y 34 pertenecían a un Centro de Menores. La técnica fue aplicada por trabajadoras sociales de uno y otro centro tras el adecuado entrenamiento.

Se obtuvo también el Indice de Características de Status (ICS del Departamento de Psicología Diferencial y del Trabajo de la Universidad Complutense de Madrid) a partir del nivel de estudios y nivel profesional de padre y madre.

En tercer lugar se pidió a los directores de los centros de EGB en los que estudiaban los niños que valoraran de 1 a 5 la posible inadaptación escolar de cada uno. En esta apreciación de la inadaptación escolar se combinan los criterios de rendimiento y comportamiento escolar. En la construcción de esta variable se representa la concepción del riesgo social general, que expresábamos antes, concretada en rasgos psicosociales claros de objetivar (el comportamiento y las calificaciones escolares) que pueden significar un peligro de inadaptación-marginación futura. Viene a ser, esta variable, la anticipación de la dependiente: riesgo social futuro. De no ser con ésta, o similar forma de anticipación, habría que recurrir a un laborioso estudio longitudinal (L. Pulkkinen, 1990), que no descarto pero sí pospongo para mejores circunstancias de economía, tiempo y personas.

La hipótesis derivada del planteamiento inicial (los estilos de vida como variable mediadora entre las características estructurales del medio y la conducta) tiene dos vertientes en sí misma:

- Una, que los estilos de vida guardarían estrecha relación con el nivel socioeconómico representado en el ICS; de manera que a mayor ICS habría unos estilos de vida por lo general menos conflictivos, y viceversa.

- Por otra parte, la mayor conflictividad de los estilos de vida estaría relacionada con una mayor inadaptación escolar, lo cual supone un claro riesgo social.

Conviene advertir que, por la ubicación del Centro de Salud en zona periférica de Alicante, la muestra total es predominantemente de clase baja. Esto, en cierta manera limita las posibilidades del estudio, ya que una muestra más variada podría hacer más patente el cumplimiento o negación de las hipótesis formuladas.

Así pues, en la medida en que las puntuaciones obtenidas con la escala cumplan los supuestos expresados, podríamos considerar la escala y técnica empleada un instrumento aceptable de apreciación del riesgo social a partir de los estilos de vida familiar. 


\section{RESULTADOS}

\section{CUADRO 1}

Correlaciones entre Status, Total Escala e Inadaptación Escolar

\begin{tabular}{lcc}
\hline & $R$ & $p$ \\
\hline ICS-Total Escala & $-0,551311$ & $5,815782 \mathrm{E}-06$ \\
Total Escala-Inadap. Escolar & 0,735434 & $<10(-6)$ \\
\hline ICS-Inadap. Escolar & $-0,478348$ & $1,2693378 \mathrm{E}-04$ \\
\hline
\end{tabular}

Podemos apreciar que los tres tipos de datos se encuentran altamente relacionados entre sí, siendo la puntuación total de la escala quien presenta valores más elevados tanto en su relación con el status como respecto a la inadaptación escolar.

El índice de características de status correlaciona negativamente tanto con el total de la escala como con la inadaptación escolar. A mayor nivel de status, aunque estamos dentro de un nivel general sensiblemente bajo, menor conflictividad de estilos de vida y menor inadaptación escolar, y viceversa.

Por otra parte, esa correlación negativa del status social es mayor respecto a la conflictividad de los estilos de vida que respecto a la inadaptación escolar.

Lo mismo ocurre con la inadaptación escolar. Esta se encuentra mucho más relacionada con los estilos de vida conflictivos que con el ICS, aunque con éste también lo esté.

Veamos a continuación si esto ocurre también con los distintos estilos de vida considerados por separado cada uno.

\section{CUADRO 2}

Correlaciones entre Estilos de Vida Parciales, Inadaptación Escolar e ICS

\begin{tabular}{lcccccc}
\hline & $1^{*}$ & 2 & 3 & 4 & 5 & 6 \\
\hline ICS & $-0,46$ & $-0,39$ & $-0,46$ & $-0,54$ & $-0,38$ & $-0,44$ \\
\hline Inadapt. Escolar & 0,61 & 0,57 & 0,60 & 0,73 & 0,44 & 0,63 \\
\hline
\end{tabular}

1 *: Hábitos. 2: Organización medio familiar. 3: Comunicación. 4: Métodos disciplinares. 5: Concepción Vida. 6: Modelos.

Todas las correlaciones representadas en el Cuadro 2 son estadísticamente significativas, con una probabilidad muy baja de ocurrir por azar (en tọdas $\mathrm{p}<0,01$ ). 
Podemos apreciar que las facetas de estilos de vida que presentan una menor relación tanto con el status como con la inadaptación escolar son la «organización del medio familiar» (2) y las formas de «concepción de vida» (5), sin duda las más complejas de calibrar en una situación de entrevista como la planteada.

En todos los casos la relación de cada una de las facetas exploradas es más fuerte con la inadaptación que con el status, manteniendo la tendencia y signo que veíamos en el Cuadro 1 respecto a la puntuación total.

\section{CONCLUSIONES}

Se confirma la relación, ya conocida de antiguo, entre status socioeconómico e inadaptación escolar y social; pero podemos apreciar ese mismo riesgo social infantil de forma más fiable a partir del estudio de formas concretas de la vida familiar. Lo cual sólo un diagnóstico más matizado y unas pautas tempranas de intervención dinámica en el funcionamiento familiar; y no sólo en los aspectos estructurales, con frecuencia inasequibles al profesional de la intervención social.

Los estilos de vida se manifiestan de forma muy sugerente como variable intermediaria entre el status social y la conducta infantil. Sin embargo, no podemos pensar que se hayan agotado todas las facetas de la vida familiar que pueden estar influyendo en el desarrollo personal y social del niño. Sin duda la ampliación del abanico de estilos de vida explorados mejoraría el pronóstico y, por tanto, la prevención.

Las facetas de «organización del medio familiar» y de «concepción de la vida» deberán ser matizadas en sucesivos estudios. La primera, a pesar de estar consolidada por los trabajos de Lautrey, suponía especial dificultad de análisis para las entrevistadoras. La segunda, original de este trabajo, es una faceta de difícil concreción que permita la discriminación social.

La forma empleada para la exploración de los estilos de vida parece adecuada al objetivo. Se obtiene, de manera discreta, sin la frialdad del cuestionario, ni la difícil intromisión de la observación, una gran cantidad de datos relativos a la vida familiar.

Si alguna utilidad práctica puede tener la apreciación del riesgo social infantil a partir de los estilos de vida familiar, radicará, sin duda, en su empleo precoz. No debe esperarse a intervenir cuando ya se ha iniciado el camino de la inadaptación. En nuestro país la mayoría de los problemas futuros de inadaptación se detectan con la entrada en la Educación General Básica, a los seis años y esto es demasiado tarde (D. M. Bryant y C. T. Ramey, 1987).

Independiente de que se exploren los estilos de vida aquí sugeridos u otros, y de que se haga con una técnica u otra, cuanto antes se rea- 
lice mayores posibilidades habrá de intervención. Por esta razón pienso que la ubicación idónea de este tipo de exploraciones es en los Centros de Atención Primaria de la Salud, dentro del programa del lactante o similar, sin óbice para su empleo en situaciones posteriores dentro de los servicios sociales.

\section{BIBLIOGRAFIA}

Apisma-Gese: Marginación social del menor. Origen, situación, alternativas. Alicante: Caja de Ahorros de Alicante y Murcia, 1981.

Bryant, D. M. y Ramey, C. T.: «Análisis de la eficacia de los programas de intervención precoz en niños en situaciones de riesgo a causa de su entorno». En M. J. Guralnick y F. C. Bennett (Dirs.): Eficacia de una intervención precoz en niños minusválidos y en situación de riesgo. Madrid: INSERSO, 1987.

Bueno, A.: Carencia económica y distorsión familiar en la adolescencia. Madrid: Editorial de la Universidad Complutense, 1990.

Hart, C. H.; Lado, G. W. y Burleson, B. B.: «Children's expectations of the autcome of social strategies: relations with sociometric status and maternal disciplinary styles». Child Development, 61, 1, págs. 127-137, 1990.

Howes, P. y Markman, H. J.: «Marital quality and child functioning: a longitudinal investigation». Child Development, 60, 5, págs. 1044-1051, 1989.

Lautrey, J.: Clase social, medio familiar e inteligencia. Madrid: Visor, 1985.

Pulkkinen, L.: "Adult life-styles and their precursors in the social behaviour of children and adolescents». European Journal of Personality, 4, 3, págs. 237-251, 1990.

Piaget, J.: L'équilibration des structures cognitives, problème central du développement. París: PUF. (Trad.: Madrid, Siglo XXI, 1978), 1975.

Vygotski, L. S.: El desarrollo de los procesos psicológicos superiores. Barcelona: Crítica, 1989. 